\title{
Substance use among adolescents in sub-Saharan Africa: A systematic review and meta-analysis
}

\author{
A Olawole-Isaac, ${ }^{1} \mathrm{PhD}$; O Ogundipe, ${ }^{2} \mathrm{PhD}$; E 0 Amoo, ${ }^{1} \mathrm{PhD}$; D Adeloye, ${ }^{3} \mathrm{PhD}$ \\ ${ }^{1}$ Demography and Social Statistics Programme, Covenant University, Ota, Nigeria \\ ${ }^{2}$ Department of Economics and Development Studies, Covenant University, Ota, Nigeria \\ ${ }^{3}$ Centre for Global Health Research, Usher Institute, University of Edinburgh, UK
}

Corresponding author: A Olawole-Isaac (adebanke.olawole-isaac@covenantuniversity.edu.ng)

\begin{abstract}
Background. In sub-Saharan Africa, substance use among adolescents has continued to be a major public health concern, albeit poorly documented across many settings.

Objective. To estimate the prevalence of substance use among adolescents in sub-Saharan Africa.

Methods. We searched Pubmed, EMBASE, AJOL and Google Scholar for population-based studies on adolescents (age 10 - 19 years) and reporting on the prevalence of substance use across sub-Saharan Africa. Search dates were from January 2000 to December 2016. A random effects meta-analysis was conducted with pooled prevalence rates (and 95\% confidence interval (95\% CI)) of estimated substance abuse among adolescents in sub-Saharan Africa.

Results. Twenty-seven studies across sub-Saharan Africa including 143201 adolescents (mean age 15.6 years) were selected. The overall prevalence of 'any substance use' in sub-Saharan Africa was $41.6 \%$, with the highest rate in Central Africa at $55.5 \%$. The use of caffeinecontaining products (including coffee or kola nut) was most predominant at 41.2\% (95\% CI 24.3 - 58.1) but limited to West Africa. These were followed by alcohol at $32.8 \%$ (95\% CI 26.0 - 39.5), tobacco products $23.5 \%$ (95\% CI 17.7 - 29.3), khat 22.0\% (95\% CI 12.5 - 31.5) and cannabis $15.9 \%$ (95\% CI 12.2 - 19.1). Other abused substances included depressants at $11.3 \%$ (95\% CI 6.5 - 16.1), amphetamines $9.4 \%$ (95\% CI 6.0 - 12.9), heroin 4.0\% (95\% CI 3.5 - 4.5) and cocaine 3.9\% (95\% CI 1.4 - 6.5).

Conclusion. Our study reflects a high use of psychoactive substances and drugs among adolescents in sub-Saharan Africa. It is important that interventions and rehabilitation programmes are comprehensive and targeted at adolescents and parents in these settings.
\end{abstract}

S Afr J Child Health 2018;12(2 Suppl 1):S79-S84. DOI:10.7196/SAJCH.2018.v12i2.1524

Substance use has become one of the growing major public health and socioeconomic issues worldwide; it has dramatically increased, particularly in developing countries. ${ }^{[1-3]}$ The analysis of substance use is complex, due in part to its varieties, degree of secrecy, health challenges and different legal connotations surrounding its use globally. The use of khat (Catha edulis), cigarettes, heroine, alcohol and other substances is a worldwide threat which especially affects young people. The World Health Organization (WHO) estimates that there are about 2 billion people worldwide who consume alcoholic beverages, of whom 76.3 million are affected by alcohol-related disorders. ${ }^{[4-8]}$ It is estimated that $9 \%$ of the global population aged $\geq 12$ years are classified as dependent on psychoactive substances. ${ }^{[9]}$ Studies have confirmed that there is a growing epidemic of tobacco, heroine and alcohol use among adolescents in the developing world, especially in southern Africa and in sub-Saharan Africa as a whole..$^{[6,10-12]}$ Khat has been used in African countries for centuries as a mild stimulant. For most youths, chewing khat is considered a method for increasing energy and elevating mood in order to improve work performance. ${ }^{[13]}$

The WHO report on substance use in southern Africa showed that negative consequences are common traits of substance use. ${ }^{[3,14]}$ These include sexual violence (e.g. rape), physical violence, criminal activity, neglect of social responsibilities, disease, injury and loss of life. Harmful effects occur with any psychoactive substance use and early initiation has been found to be associated with an increased risk of developing addiction and adulthood dependence. ${ }^{[3,15]}$ In general, it has been shown that the use of cigarettes, alcohol and other substances is a worldwide threat that affects young people. ${ }^{[3,16]}$ In some parts of Ethiopia, such as Bale and Harar, khat chewing in communities in which smoking is common is seen as a social custom that dates back thousands of years. Many students also consider khat chewing as a method of improving their reading ability. However, no activity has been seen in the reduction of substance use. ${ }^{[17,18]}$

While substance use is not new in research parlance, ${ }^{[1]}$ the high level of ingenuity among young people (especially adolescents) that has resulted in numerous complex mixtures, experimentation and discoveries of new materials and volatile solvents (or inhalants) that can be drunk or inhaled with immediate intoxicating effect or other diverse consequences, ${ }^{[11]}$ could make continuous research on this menace relevant. The prevalence of substance use varies from country to country and time to time. Regular updates on substance use and its associated factors could therefore hold significant input regarding appropriate and dynamic interventions towards reduction or eradication of substance use among adolescents, not only in southern Africa but also worldwide. ${ }^{[19,20]}$ The present study therefore aims to assess the prevalence of substance use among adolescent in sub-Saharan Africa as a way forward towards strengthening the prevention and treatment of harmful use of substances that could enhance achievement of the proposed indicator of Sustainable Development Goal (SDG-3.5) in the region of study.

\section{Methods}

\section{Search strategy and selection criteria}

We conducted a systematic review to identify population-based (cross sectional or cohort) studies related to substance use among adolescents in outhern Africa. We searched the PubMed database, Google Scholar and AJOL for studies published between 1 January 2000 and 31 December 2016 (for search terms). This period was selected to cover the millennium years $(2000$ - 2015) and the immediate 2016 that was coincidentally the year of special sessions 
on drugs in the United Nations (United Nations General Assembly Special Session on Drugs (UNGASS)). We also searched online journals and scanned the reference lists of identified reports. The search terms used were substance use or drug use or substance abuse or drug abuse or substance misuse or drug misuse), adolescents or adolescence and sub-Saharan Africa or Africa). These search terms were obtained from Medical Subject Headings (MeSH). We included studies of substance use providing numerical estimates of prevalence, case and determinants of substance use. We excluded non-human studies, studies without clearly defined study designs, methodologies for substance use, and review articles (Fig. 1). We applied no language restrictions.

\section{Procedures}

We defined substance use as lifetime use of any type of substance or drug. We extracted all data onto a template in Microsoft Excel file format. We abstracted data systematically by age and various severity categories of all-cause substance use, including the number of cases or incidence of substance use, among adolescents (age 10 - 19), and their corresponding 95\% confidence intervals (CIs) for cases of use and non-use adolescent (with Stata 13.1 (StataCorp., USA)). The data were extracted by two independent reviewers and emerging disagreement was resolved after discussion. We also contacted authors who were reachable for additional data when data in published studies were not conducive to inclusion in the meta-analysis.

A random effect meta-analysis (DerSimonian and Laird method) was conducted on extracted crude prevalence rate of substance use and their determinants to accommodate heterogeneity across studies included in the analysis. ${ }^{[21,22]}$ Overall summaries of the metaestimates (and CIs) were reported separately. We accounted for variation in sample sizes from each data point and controlled for year of publication to generate estimates of substance use prevalence for each substance, respectively. Heterogeneity between studies was assessed using I-squared $\left(\mathrm{I}^{2}\right)$ statistics, and subgroup analysis was conducted to detect causes of heterogeneity when appropriate.

\section{Results}

\section{Search results}

Our search returned 1765 publications. After screening titles for relevance (studies estimating the burden of substance use), 880

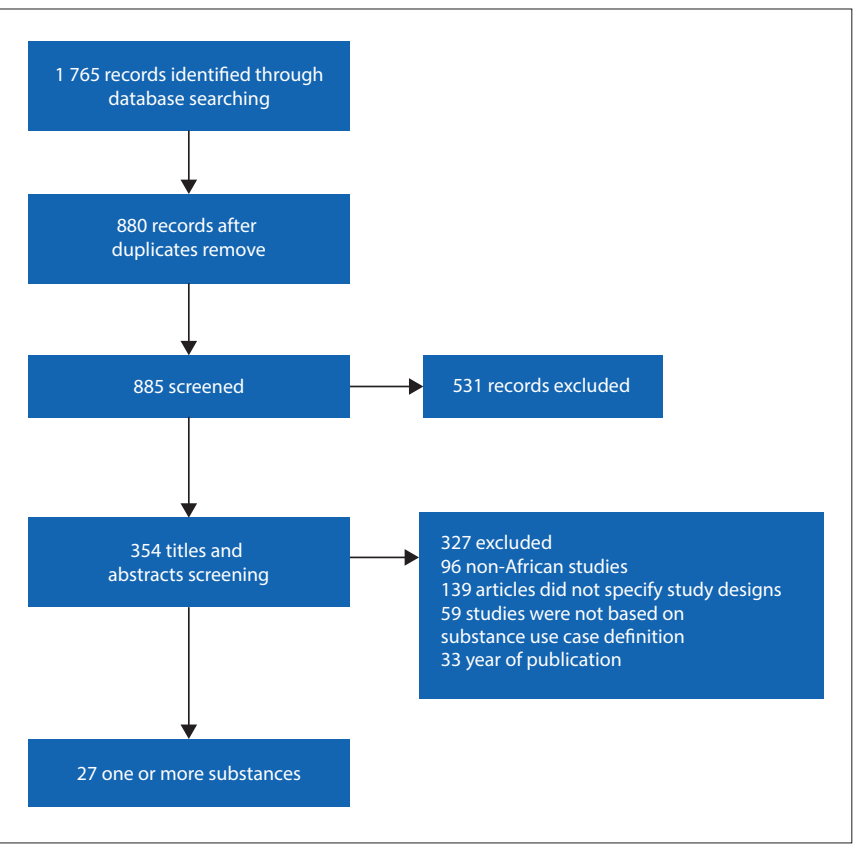

Fig. 1. Study selection flow chart. studies were excluded. We therefore assessed 885 full-text papers. After applying the quality criteria, 531 studies were excluded because they could not provide prevalence data on substance use, population figures or relevant estimates from which prevalence can be calculated; another 327 articles did not specify study designs, out of which 265 studies were not based on substance use case definitions and non-African studies; 10 studies looked at only one substance and 17 studies examined more than one substance. A total of 27 studies were retained for review.

\section{Study characteristics}

Table 1 shows the mean age, region, country and study year. The mean of the study population was 15.6 years, while the study covered 4 regions in Africa. West African countries recorded the highest percentage of the various drugs covered $(46.7 \%$, as indicated in Table 1). The study year covered years 2000 to 2016; and in year 2011 alone, $26.3 \%$ of the various substance use was identified. Out of the study locations, Nigeria represented a total of $40 \%$ of the studies on substance use in the present study.

The estimated proportion of any substance use among adolescents in sub-Saharan Africa was $41.6 \%$ (95\% CI 31.3 - 51.9) (Fig. 2). In the regional subgroup analysis, Central Africa had the highest proportion of any substance use among adolescents at 55.5\% (95\% CI 53 - 58), followed by East Africa at 48.99\% (95\% CI 28.8 - 69.2), and West Africa at 38.3\% (95\% CI 24.5 - 52.2). Southern Africa had the lowest proportion of any substance use among the adolescents at $37 \%$ (95\% CI 16.1 - 57.8).

\section{Table 1. Characteristics of the studied population}

\begin{tabular}{|c|c|c|c|}
\hline $\begin{array}{l}\text { Mean age } \\
\text { identified }\end{array}$ & $N(\%)$ & $\begin{array}{l}\text { Study by } \\
\text { country }\end{array}$ & $N(\%)$ \\
\hline 12.6 & $3(2.6)$ & Congo & $3(2.5)$ \\
\hline 13.5 & $1(0.9)$ & Ethiopia & $9(7.5)$ \\
\hline 14 & $17(14.8)$ & Gabon & $5(4.2)$ \\
\hline 14.1 & $1(0.9)$ & Ghana & $8(6.7)$ \\
\hline 14.3 & $4(3.5)$ & Kenya & $17(14.2)$ \\
\hline 14.5 & $4(3.5)$ & Nigeria & $48(40.0)$ \\
\hline 14.9 & $1(0.9)$ & South Africa & $29(24.2)$ \\
\hline 15 & $9(7.8)$ & Zimbabwe & $1(0.8)$ \\
\hline 15.1 & $1(0.9)$ & Total & $120(100)$ \\
\hline 15.2 & $15(13.0)$ & Study year & \\
\hline 15.9 & $17(14.8)$ & 2000 & $9(7.6)$ \\
\hline 16 & $11(9.6)$ & 2001 & $1(0.8)$ \\
\hline 16.1 & $2(1.7)$ & 2002 & $8(6.8)$ \\
\hline 16.4 & $1(0.9)$ & 2005 & $12(10.2)$ \\
\hline 17 & $11(9.6)$ & 2006 & $1(0.8)$ \\
\hline 17.2 & $7(6.1)$ & 2008 & $5(4.2)$ \\
\hline 17.4 & $4(3.5)$ & 2010 & 14 (11.9) \\
\hline 18.3 & $5(4.3)$ & 2011 & $31(26.3)$ \\
\hline 21.9 & $1(0.9)$ & 2012 & $9(7.6)$ \\
\hline Total & $115(100)$ & 2013 & $21(17.8)$ \\
\hline $\begin{array}{l}\text { Mean age } 15.6 \\
\text { years }\end{array}$ & & 2014 & $5(4.2)$ \\
\hline Region & & 2015 & $1(0.8)$ \\
\hline Central & $8(6.7)$ & 2016 & $1(0.8)$ \\
\hline East & $26(21.7)$ & Total & $118(100)$ \\
\hline South & $30(25.0)$ & & \\
\hline West & $56(46.7)$ & & \\
\hline Total & $120(100)$ & & \\
\hline
\end{tabular}


Table 2. Characteristics of the included studies

\begin{tabular}{|c|c|c|c|c|c|c|c|c|c|}
\hline First author & Year & Location & Design & $\begin{array}{l}\text { Case } \\
\text { definition }\end{array}$ & Gender & $\begin{array}{l}\text { Data type } \\
\text { (substance) }\end{array}$ & $\begin{array}{l}\text { Mean } \\
\text { age }\end{array}$ & $\begin{array}{l}\text { Sample } \\
\text { adolescent } \\
\text { population }\end{array}$ & $\begin{array}{l}\text { Prevalence } \\
(\%)\end{array}$ \\
\hline Deressa $^{[7]}$ & 2009 & Ethiopia & CS & LU & Both & All & 15.9 & 225 & 31.4 \\
\hline $\mathrm{Madu}^{[24]}$ & 2002 & SA & CS & $\mathrm{EU}$ & Both & All & 17.2 & 435 & 19.8 \\
\hline Mashita $^{[25]}$ & 2005 & SA & CS & $\mathrm{CU}$ & Both & All & 14.5 & 1654 & 9.9 \\
\hline Mimbila-Mayi ${ }^{[26]}$ & 2008 & Gabon & CS & $\mathrm{EU}$ & Both & All & 14.5 & 1469 & 55.5 \\
\hline Palen ${ }^{[27]}$ & 2006 & Nigeria & CS & $\mathrm{LU}$ & Both & All & 14 & 2182 & 46.8 \\
\hline Oshodi $^{[29]}$ & 2005 & Nigeria & CS & $\mathrm{CU}$ & Both & All & 15.9 & 402 & 28.1 \\
\hline Igwe ${ }^{[30]}$ & 2010 & Nigeria & CS & $\mathrm{LU}$ & Both & All & 15 & 900 & 32.2 \\
\hline $\operatorname{Dida}^{[31]}$ & 2013 & Ethiopia & CS & $\mathrm{CU}$ & Both & All & 18.4 & 603 & 34.8 \\
\hline Embleton $^{[32]}$ & 2011 & Kenya & CS & LU & Both & All & 14 & 146 & 29 \\
\hline Abdulkarim ${ }^{[33]}$ & 2000 & Nigeria & CS & $\mathrm{LU}$ & Both & All & 15.9 & 1200 & 40.1 \\
\hline Famuyiwa $^{[34]}$ & 2011 & Nigeria & CS & LU & Both & All & 15.2 & 4286 & 52.4 \\
\hline Oppong Asante ${ }^{[35]}$ & 2012 & Ghana & CS & EU & Both & All & 12.6 & 227 & 28.2 \\
\hline Atitola $^{[36]}$ & 2013 & Nigeria & CS & EU & Both & All & 15.1 & 538 & 21.4 \\
\hline $\operatorname{Doku}^{[37]}$ & 2008 & Ghana & CS & LU & Both & All & 15 & 1195 & 45.8 \\
\hline Fakier $^{[38]}$ & 2011 & SA & CS & EU & Both & All & 16 & 703 & - \\
\hline Carney $^{[39]}$ & 2001 & SA & CS & LU & Both & All & 17.6 & 1470 & 43.3 \\
\hline Pluddeman ${ }^{[40]}$ & 2006 & SA & CS & EU & Both & Methamphetamine & 14.9 & 1561 & 8.8 \\
\hline Onya $^{[41]}$ & - & SA & CS & $\mathrm{EU}$ & Both & Alcohol & 16.4 & 1600 & 22.4 \\
\hline Ogwell $^{[42]}$ & 2001 & Kenya & CS & LU & Both & Tobacco & - & 1130 & 31 \\
\hline Chivandire $^{[43]}$ & 2015 & Zimbabwe & CS & $\mathrm{EU}$ & Both & Cannabis & 16.8 & 350 & 15.6 \\
\hline Mabiala Babela ${ }^{[44]}$ & $2001 / 2$ & Congo & CS & LU & Both & Alcohol & - & 4315 & 22.8 \\
\hline
\end{tabular}

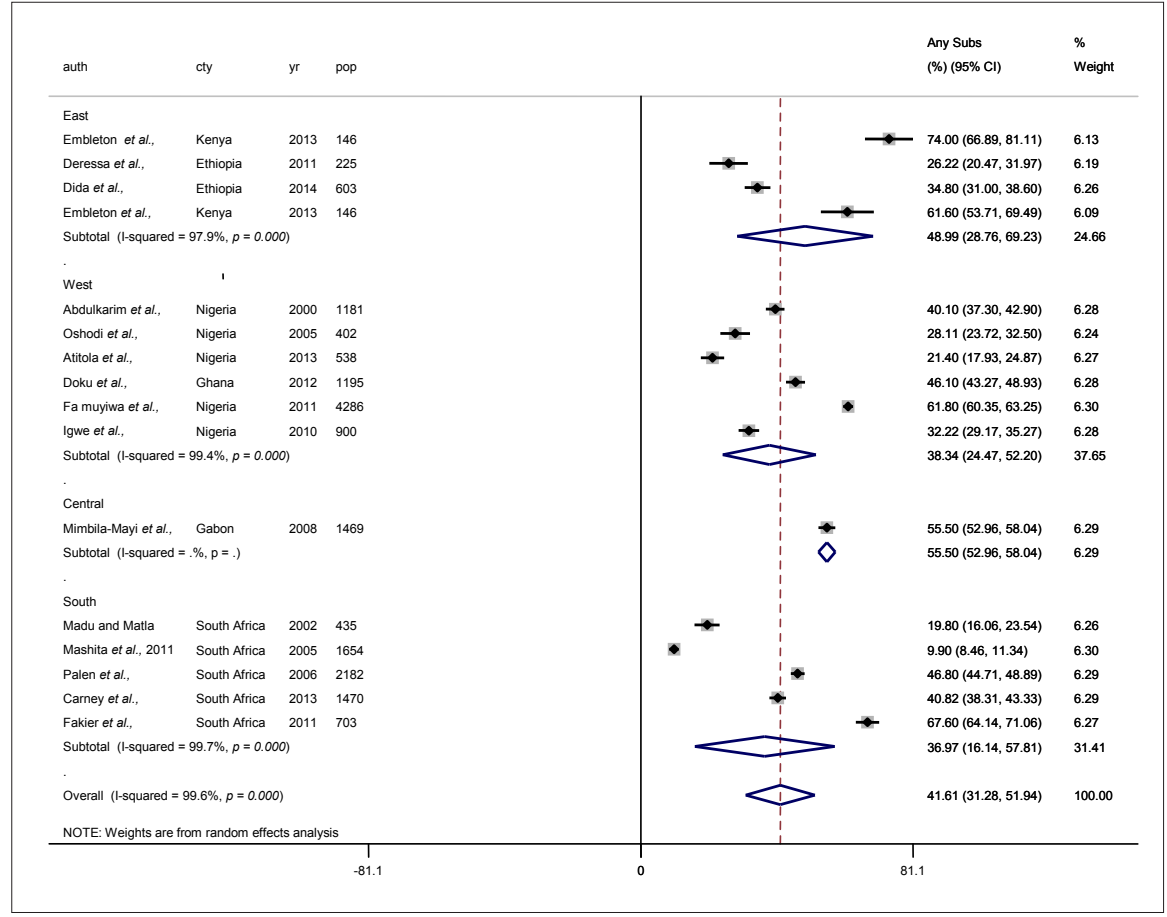

Fig. 2. Forest plots of any substance use among adolescents.

Forest plots were used to give a visual assessment of the pooled crude prevalence along with $95 \%$ CIs of tobacco use by the sub-regions studied. We used the $\mathrm{I}^{2}$-statistic to evaluate heterogeneity in tobacco prevalence between the retained studies.
(95\% CI 30.3 - 60.9), followed by the SouthEast Region at 25.6\% (95\% CI 12.7 - 38.5), Central Africa at $12.0 \%$ (95\% CI -6.6 - 30.6), and West Africa at $11.8 \%$ (95\% CI 7.8-15.8) respectively (Fig. 3).

The estimated proportion of alcohol use among adolescents in sub-Saharan Africa was $32.77 \%$ (95\% CI 26-39.5) (Fig. 4). In the regional subgroup analysis, southern Africa had the highest proportion of alcohol use among the adolescents at $40.82 \%$ (95\% CI 22.5-59.2), followed by East Africa at $34.25 \%$ (95\% CI 21.8-46.7) and Central Africa at 29.09\% (95\% CI 6.9-51.3), respectively. West Africa had the lowest proportion of alcohol use among the adolescents at $28.21 \%$ (95\% CI 18.5-37.9).

Fig. 5 shows the assessment of the pooled crude prevalence along with 95\% CIs of inhalant use by sub-region studied. It is interesting to note that 'inhalant' was not a type of substance use indentified from the retained study in Central Africa. The overall prevalence was higher among East Africa (45.5\%; CI 21.2 - 69.8) than for South Africa (10.5\%; CI 2.9 - 18.1) and West Africa (8.5\%; CI 5.0 - 11.9).

The proportion of adolescents who use cannabis in sub-Saharan Africa was 15.65\% (95\% CI 12.1 - 19.1) (Fig. 6). Sub-regionally, East Africa had the highest proportion of cannabis use among the adolescents at $28.9 \%$ (95\% CI 23.7 - 34.1), followed by southern 


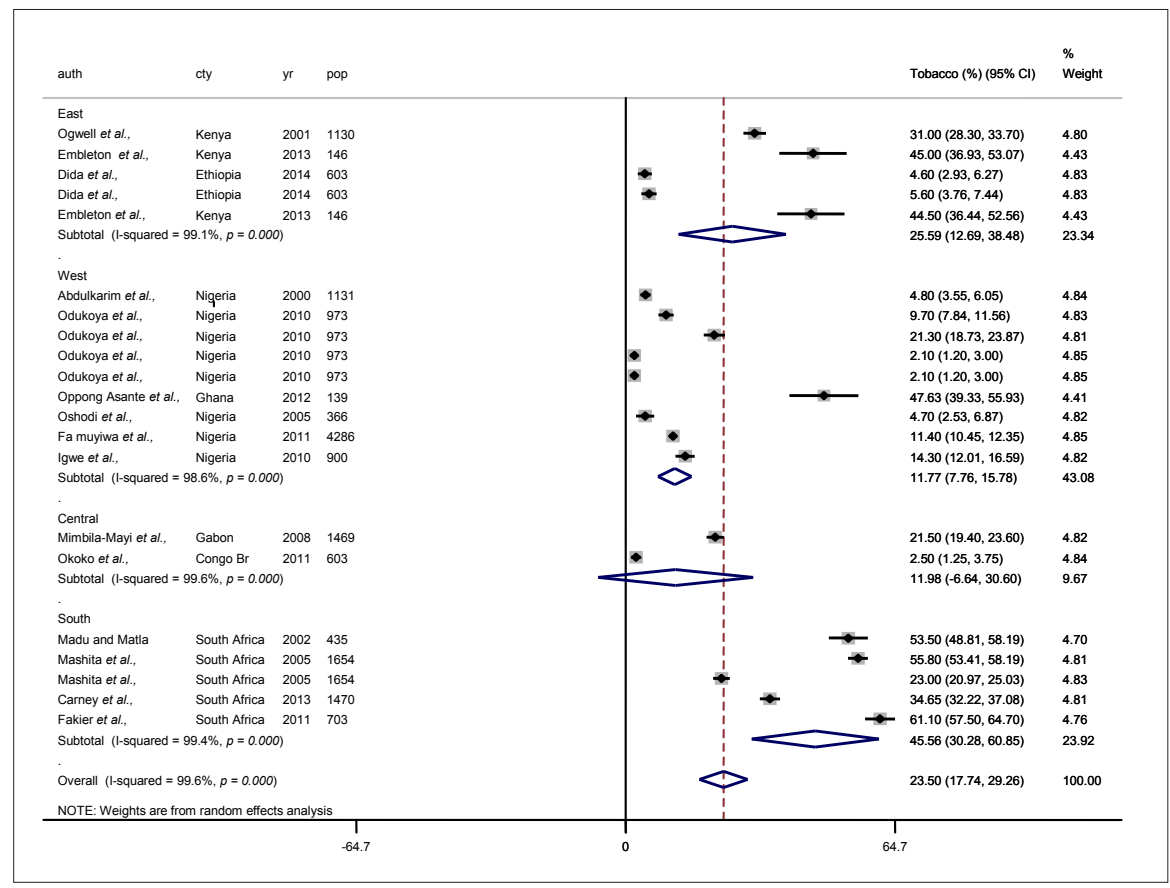

Fig. 3. Forest plots of tobacco use among adolescents.

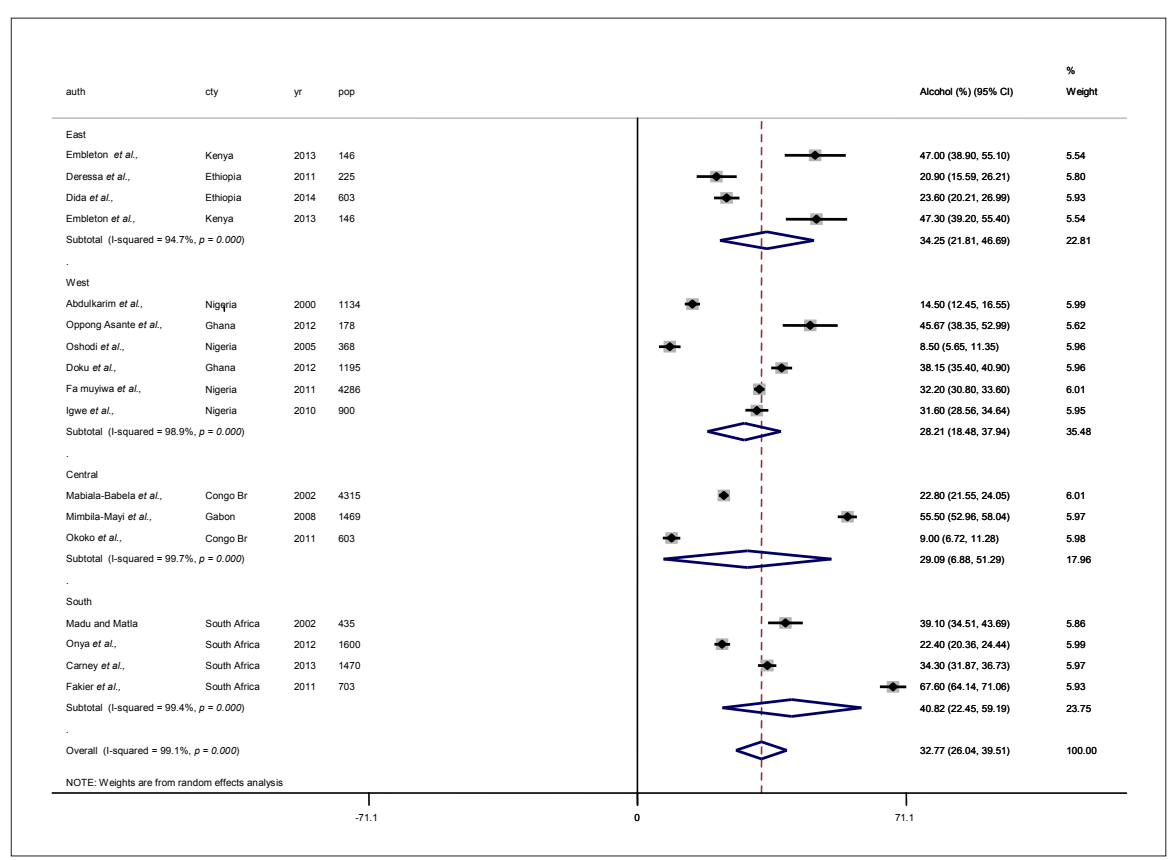

Fig. 4. Forest plots of alcohol use among adolescents.

Africa at $25.7 \%$ (95\% CI 13.9 - 37.5), then West Africa at 7.06\% (95\% CI 4.5 - 9.6). The lowest proportion of cannabis use among the adolescents was in Central Africa at $4.9 \%$ (95\% CI 3.8 - 6). The proportion of cocaine use was $41.6 \%$ (95\% CI 31.3 51.9). From the sub-region estimation, the highest proportion of cocaine use was in southern Africa at 5.93\% (95\% CI 2 - 9.9), followed by West Africa at $4.16 \%$ (95\% CI 3.2 - 5.1), with Central Africa having the lowest proportion of cocaine use at $0.1 \%$ (95\% CI -0.06- 0.26); data were unavailable for East Africa.
Results further showed the assessment of the pooled crude prevalence along with $95 \%$ CIs of khat use by sub-regions studied. It is interesting to note that khat was identified only in East Africa from the retained study, with a prevalence of $22.0 \%$; CI $12.4-31.5$ ) while tranquiliser showed a prevalence of $12.2 \%$ (CI 6.9 - 17.8) and in South Africa of $7.4 \%$ (CI 5.5 - 9.4) respectively.

\section{Discussion}

An accurate understanding of the prevalence and drivers of substance use among adolescents is indispensable for the prevention and treatment of substance use and harmful use of alcohol, as enshrined in the Sustainable Development Goals (SDG3.5). The present study has therefore provided broad empirical evidence from available studies on substance use among adolescents in sub-Saharan Africa and highlighted some of their prevalences. We adopted a systematic review and meta-analysis as distinct from several narrow individual researches. The basic idea was to underscore without bias. Researchers conducting systematic reviews use explicit methods aimed at minimising bias, at reliable information on the extent of substance abuse within the context of sub-Saharan Africa, and for possible interventions from stakeholders. ${ }^{[23,24]}$

One of the major contributions of the present study is the identification of alcohol and tobacco as the highest prevailing substances and the adolescents in the study locations. All four regions covered in this study showed a high prevalence of alcohol and tobacco compared with other substances used. More specifically, the high prevalence rates of alcohol and tobacco use (i.e. $40.8 \%$ and $45.6 \%$, respectively) obtained from the analysis are higher than those obtained in other studies. ${ }^{[1,25-28]}$

Furthermore, estimates from the present study on the use of cannabis $(7.09 \%)$ in West and Central, ${ }^{[29]}$ while estimates from the present study on cocaine use $(4.16 \%)$ are higher than the 2012 estimates $(0.69 \%)$ reported in the World Drug Report 2015. ${ }^{[30]}$ This finding, however, shows that the use of cannabis among adolescents in these regions is lower than the societal average, while the use of cocaine among adolescents is higher than the societal average Overall, this trend indicates the possibility of increased access to these substances and a higher incidence of drug-related disorders as a result of their use. The fact that substance use or drugs could be inimical to young people's health, education and overall wellbeing, including academic performance ${ }^{[31-33,45,46]}$ makes a continuous investigation of this menace a worthwhile task, notwithstanding the existence of other studies. Besides, considering the proportion of the adolescent population in sub-Saharan Africa who are mostly approaching the prime age of life, a more encompassing programme could be pivotal in attempting to salvage the potential roles of this youth in the economic development of their countries rather than allowing substance use to erode such inherent benefits.

\section{Conclusion and recommendations}

The present study reflects a high use of psychoactive substance and drugs among adolescents in sub-Saharan Africa. The fact that parental factors have significant 


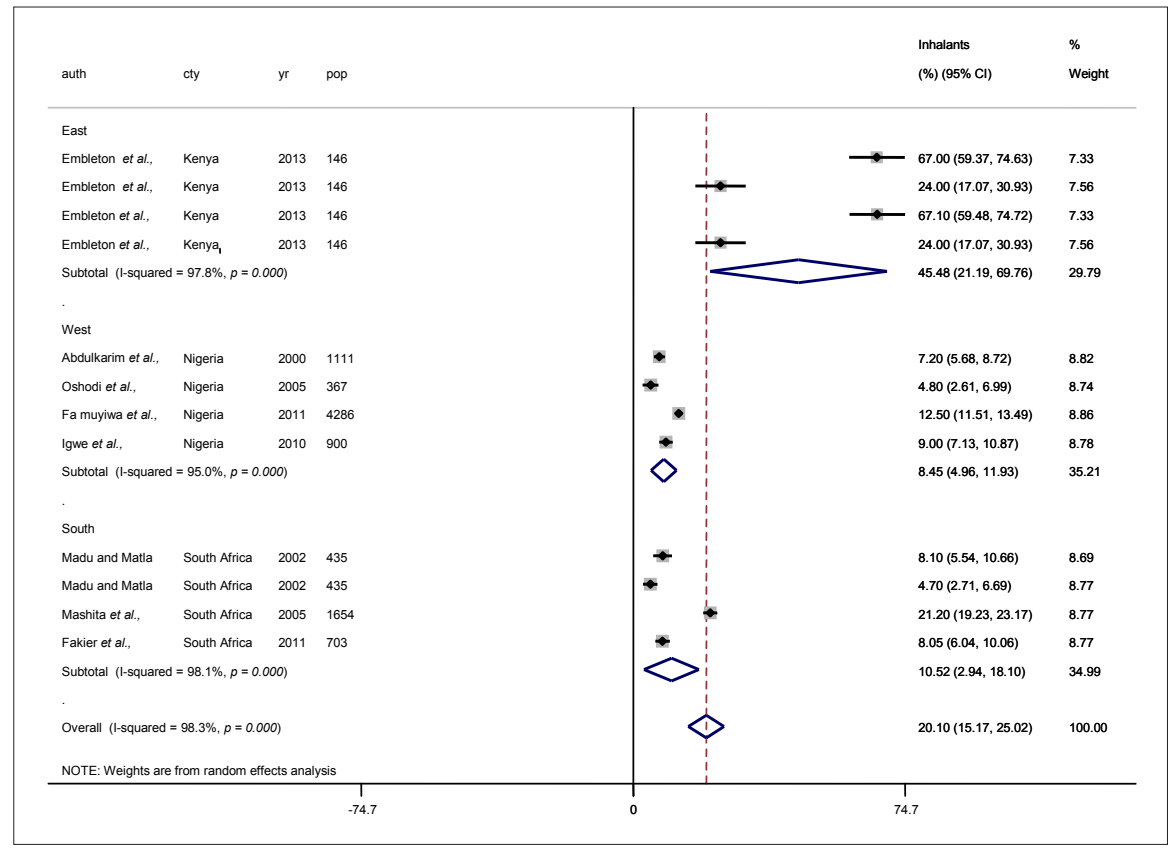

Fig. 5. Forest plots of inhalant use among adolescents.

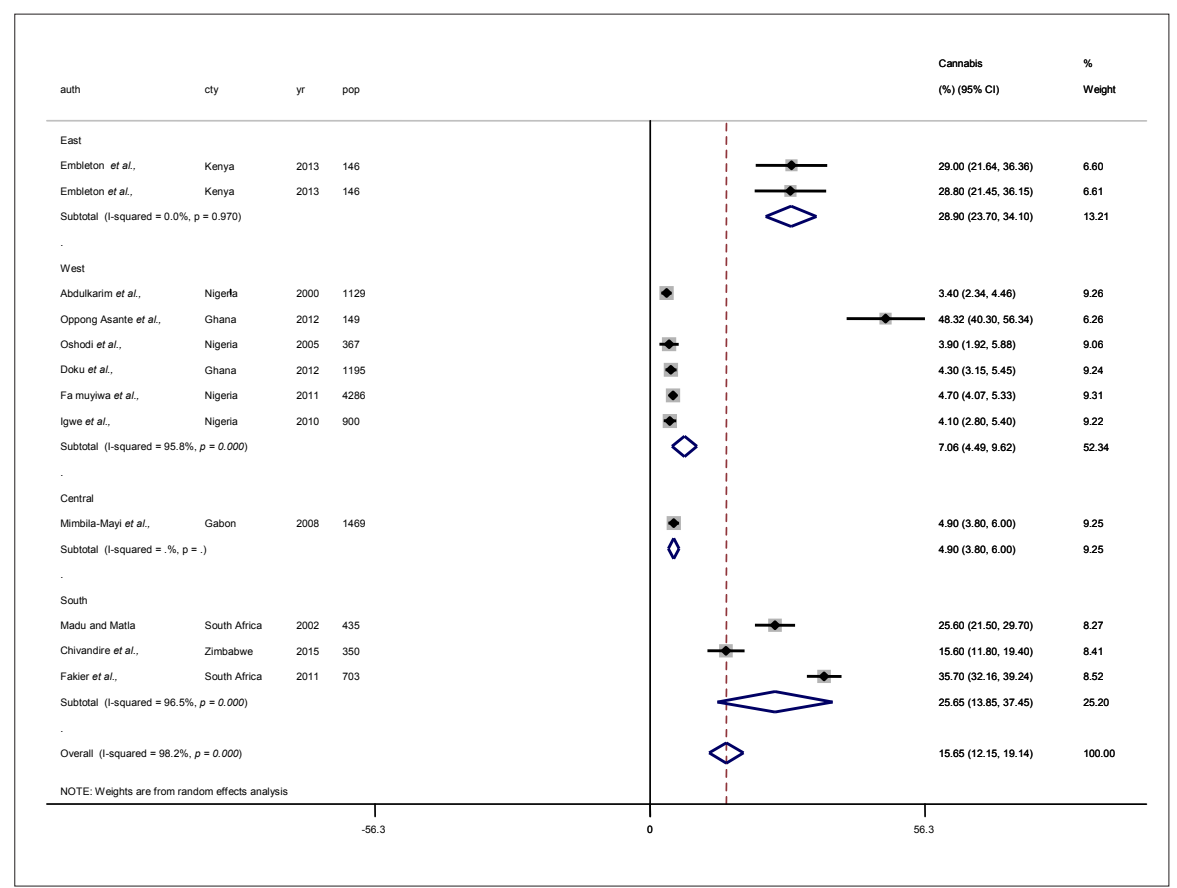

Fig. 6. Forest plots of cannabis use among adolescents.

influence on adolescent use of substances would require home-based counselling among parents, thus ensuring holistic aid and treatment of substance use for parents and children. The authors suggest appropriate guidance and counselling in the proper use of drugs, and holistic policies that might discourage unnecessary substance and alcohol use among parents and adolescents in the study's regions of research.

Acknowledgements. The authors gratefully acknowledge the authors of articles used in this study for their permission to access and use
$\mathrm{AO}$ and $\mathrm{OO}$ conducted data extraction with oversight from DA. AO and DA conducted the analysis. AO drafted the paper. AO, OO, EA and DA contributed to the final writing of the paper and checked important intellectual content. All authors approved the final draft of the manuscript.

Funding. None.

Conflicts of interest. None.

1. Adekeye OA, Adeusi SO, Chenube O, Ahmadu FO, Sholarin MA. Assessment of alcohol and substance use among undergraduates in selected private universities in southwest Nigeria. IOSR J Humanities and Social Science 2015;20(3):1-7.

2. Odejide A. Status of drug use/abuse in Africa: A review. Int $J$ Mental Health and Addiction 2006;4(2):87-102

3. World Health Organization (WHO). Substance Use in South Africa: Knowledge, Attitudes, Practices, and Opportunities for Intervention. Geneva: World Health Organization; 2003. http:// www.who.int/mental_health/media/en/707.pdf (accessed 12 December 2017).

4. World Health Organization (WHO). Global Status Report on Alcohol 2004. Geneva: WHO, 2004.

5. Bbosa GS, Kyegombe DB, Anokbonggo WW, Lubega A, MugishaA, Ogwal-Okeng J. Effect of chronic alcohol consumption on the red blood cell count and RBC indices in the HIV infected patients on $\mathrm{d} 4 \mathrm{~T} / 3 \mathrm{TC} / \mathrm{NVP}$ drug regimen in Uganda. Int J Basic Clin Pharmacol 2017;2(5):528-536.

6. Bandason T, Rusakaniko S. Prevalence and associated factors of smoking among secondary school students in Harare Zimbabwe. Tobacco Induced Diseases 2010;8(1):12.

7. Deressa W, Azazh A. Substance use and its predictors among undergraduate medical students of Addis Ababa University in Ethiopia. BMC Public Health 2011;11(1):660.

8. Kalix P. Khat: Scientific knowledge and policy issues. Addiction 1987;82(1):47-53.

9. Volkow ND, Li TK. Drugs and alcohol: treating and preventing abuse, addiction and their medical consequences. Pharmacol Ther. 2005;108:3-17

10. Amoo EO, Igbinoba AO, Osarieme A, et al. Trends, Drivers and Health Risks of Adolescent Fatherhood in sub-Saharan Africa. 4th International Conference on Education, Social Sciences and Humanities, held in Dubai, UAE, 10-12 July 2017.

11. Wechsberg WM, Luseno W, Riehman K, Karg R, Browne F, Parry C. Substance use and sexual risk within the context of gender inequality in South Africa. Substance Use and Misuse 2008;43(89):1186-1201.

12. Ethiopia Demographic and Health Survey 2011 Central Statistical Agency, Addis Ababa, Ethiopia and ICF International, Calverton, Maryland, USA; March 2012.

13. Kebede Y. Cigarette smoking and khat chewing among college students in North West Ethiopia. Ethiopian Journal of Health Development 2002;16(1):9-17.

14. Makhura MJ. An investigation of the causes of substance abuse by learners in the Waterberg District of Limpopo Province: A case study. Doctoral dissertation, University of Limpopo, Turfloop Campus; 2011.

15. Soldera M, Dalgalarrondo P, Corrêa Filho HR, Silva CA. Uso de drogas psicotrópicas por estudantes: Prevalência e fatores sociais associados. Revista de Saúde Pública 2004;38(2):277-283.

16. World Health Organization. Environmental Health in Emergencies and Disasters: A Practical Guide. Geneva: WHO; 2002.

17. DerSimonian R, Laird N. Meta-analysis in clinical trials. Controlled Clinical Trials 1986;7(3):177-188 
18. IntHout J, Ioannidis JP, Borm GF. The Hartung-Knapp-Sidik-Jonkman method for random effects meta-analysis is straightforward and considerably outperforms the standard DerSimonian-Laird method. BMC Medical Research Methodology 2014;14(1):25.

19. Magarey JM. Elements of a systematic review. Int J Nursing Practice 2001;7(6):376-382.

20. Moher D, Shamseer L, Clarke M, et al. Preferred reporting items for systematic review and meta-analysis protocols (PRISMA-P) 2015 statement. Syst Rev 2015;4(1):1.

21. Fletcher JM, Wolfe BL. The effects of teenage fatherhood on young adult outcomes. Economic Inquiry 2012;50(1):182-201.

22. Murray CE, King K, Crowe A. Understanding and addressing teen dating violence implications for family counselors. Family J 2016;24(1):52-59.

23. National Fatherhood Initiative. Statistics on the Father Absence Crisis in America. Germantown: National Fatherhood Initiative; 2016.

24. Madu SN, Matla MP. Correlations for perceived family environmental factors with substance use among adolescents in South Africa. Psychological Reports 2003;92:403-415

25. Mashita RJ, Themane MJ, Monyeki KD, Kemper HCG. Current smoking behaviour among rural South African children: Ellisras Longitudinal Study. BMC Pediatrics 2011;11(58):1-8

26. Mimbila-Mayi M, VierinYN, Biloghe A, Moussavou-Mouyama A. Consumption of addictive substances by Gabonese teenagers: An epidemiological survey. Sante 2011;21(3):149-152

27. Palen, L, Smith EA, Flisher AJ, Caldwell LL, Mpofu E. Substance use and sexual risk behavior among South African eighth grade students. J Adolescent Health 2006;39:761-763.

28. UNODC. World Drug Report 2015. New York: United Nations Office on Drugs and Crime; 2015.

29. Oshodi, OY, Aina, OF, Onajole, AT. Substance use among secondary school students in an urban setting in Nigeria: Prevalence and associated factors. African Journal of Psychiatry 2010;13:52-57.

30. Igwe WC, Ojinnaka NC. Mental health of adolescents who abuse psychoactive substances in Enugu, Nigeria - a cross-sectional study. Italian J Pediatrics 2010;36:53.

31. Dida N, Kassa Y, Sirak T, Zerga E, Dessalegn T. Substance use and associated factors among preparatory school students in Bale Zone, Oromia Regional State, Southeast Ethiopia. Harm Reduction Journal 2014;11:21.

32. Embleton L, Atwoli L, Ayuku D, Braitstein P. The journey of addiction: Barriers to and facilitators of drug use cessation among street children and youths in Western Kenya. PLoS One 2013;8(1):e53435. https://doi.org/10.1371/journal. pone. 0053435

33. Abdulkarim AA, Mokuolu OA, Adeniyi A. Drug use among adolescents in Ilorin, Nigeria. Trop Doctor 2005;35(4):225-228.
34. Famuyiwa O, Aina OF, Bankole-Oki OM . Epidemiology of psychoactive drug use amongst adolescents in metropolitan Lagos, Nigeria. Eur Child Adolesc Psychiatry 2011;20:351-359

35. Oppong Asante K, Meyer-Weitz A, Petersen I. Substance use and risky sexual behaviours among street connected children and youth in Accra, Ghana. Subs Abuse Treat Prev Policy 2014;9:45.

36. Atitola O, Ayinde O, Adeitan O. African Health Sciences 2013;13(3):777-784 http://dx.doi.org/10.4314/ahs.v13i3.37

37. Doku D, Koivusilta L, Rimpela A. Socioeconomic differences in alcohol and drug use among Ghanaian adolescents. Addictive Behaviors 2012;37:357-360.

38. Fakier N, Wild LG. Associations among sleep problems, learning difficulties and substance use in adolescence. Journal of Adolescence 2011;34:717-726.

39. Carney T, Browyn JM, Louw J, Lombard C, Flisher AJ. The relationship between substance use and delinquency among high-school students in Cape Town, South Africa. Journal of Adolescence 2013;36:447-455.

40. Pluddemann A, Flisher AJ, McKetina R, Parry C, Lombard C. Methamphetamine use, aggressive behavior and other mental health issues among high school students in Cape Town, South Africa. Drug and Alcohol Dependence 2010; 09:14-19.

41. Onya H, Tessera A, Myers B, Flisher A. Community influences on adolescents' use of home-brewed alcohol in rural South Africa BMC Public Health 2012;12:642. https://doi.org/10.1186/1471-2458-12-642

42. Ogwell AE, Astrom AN, Haugejorden O. Socio-demographic factors of pupils who use tobacco in randomly-selected primary schools in Nairobi province, Kenya. East African Medical Journal 2003;80(5):235-241.

43. Chivandire CT, January J. Correlates of cannabis use among high school students in Shamva District, Zimbabwe: A descriptive cross-sectional study. Malawi Medical Journal 2016;28(2):53-56.

44. Mabiala-Babela JR, Mahoungou-Guimbi KC, Massamba A, Senga P. [Alcohol consumption among teenagers in Brazzaville (Congo)]. Sante 2005;15(3):153-160.

45. Van Heerden MS, Grimsrud AT, Seedat S, Myer L, Williams DR, Stein DJ. Patterns of substance use in South Africa: Results from the South African Stress and Health study. S Afr Med J 2009; 99(5 Pt 2):358-366.

46. Reddy P, Swart D. Preliminary Report on Global Youth Tobacco Survey 2002. KwaZulu-Natal: Medical Research Council; May 2003. www.who.int/entity/ tobacco/surveillance/South\%20Africa\%20GYTS\%20Report\%202002.pdf (accessed 12 April 2018).

Accepted 19 April 2018. 